\title{
Eco-friendly plant growth and development regulators on the basis of derivatives 1,2,4- triazines
}

\author{
E.A. Builova*, A.K. Mazitova, G.K. Aminova, I.I. Zaripov, and A.H. Alibakova \\ Ufa State Petroleum Technological University, Ufa, Russia
}

\begin{abstract}
The article considers the application of plant growth and development regulators, in particular, derivatives of asymmetric triazines. A method for obtaining hexahydro-1,2,4-triazinone-3 is given. Optimal conditions for the reaction of 1,2-dichloroethane with semicarbazide are determined: reaction time, process temperature, and the effect of solvents on the yield of the target product. The results of laboratory and vegetation tests of 1,2,4-triazinone-3 for biological activity are presented. Laboratory studies were carried out on seeds of wheat, cucumbers, radish and vetch, which were laid out in Petri dishes and poured with a working solution, the concentration of the drug is $1,10 \mathrm{mg} / \mathrm{l}$. Two days later, the length and weight of etiolated seedlings were determined. Vegetation tests were carried out on seeds of barley, wheat and rye with a concentration of 10 $\mathrm{mg} / \mathrm{l}$. After two weeks, the length and weight of the plants were measured.
\end{abstract}

\section{Introduction}

In agriculture, plant growth and development regulators (PGDR) are widely used in practice. Figure 1 shows the classification of PPRS, which help plants better tolerate adverse environmental conditions, increase their survival rate and increase fruiting [1-4].

Of particular interest from the point of view of the efficiency of the growth-regulating properties are nitrogen-containing heterocycles, in particular derivatives of symmetric and asymmetric triazines. Compounds of symmetric derivatives have found practical application, however, they are difficult to biodegrade and accumulate in the soil, and as a consequence in the plants itselves. Therefore, more environmentally friendly for humans and the environment are the asymmetric triazines, which are easily decomposed in the environment as they do not suppress the activity of nitrification and nitrogen-fixing bacteria, hence are relatively low-resistance in environmental objects and are relatively rapidly decomposed to form the simplest products [5-9].

\footnotetext{
* Corresponding author: evg-builova@yandex.ru
} 


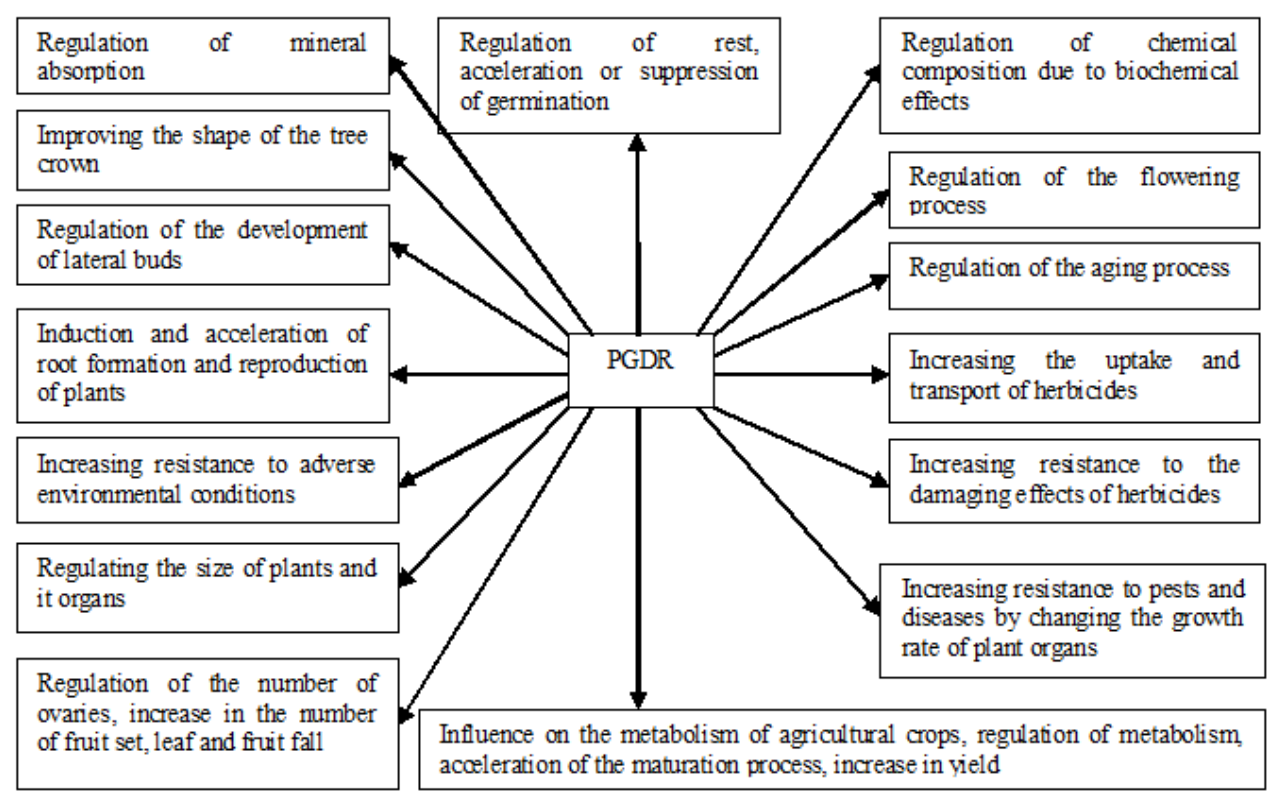

Fig. 1. Scheme of influence of growth and development regulators on agricultural crops.

\section{Materials and methods}

The aim of our work is to obtain derivatives of 1,2,4-triazines, in particular hexahydro-1,2,4 triazinone-3 based on semicarbazide and to study its growth-regulating activity.

A three-necked flask equipped with a mechanical stirrer, reflux condenser and dropping funnel was charged with $30 \mathrm{ml}$ of dimethyl sulfoxide (DMSO); $5.57 \mathrm{~g}$ (0.05 mol) semicarbazide, $5.3 \mathrm{~g}(0.05 \mathrm{~mol})$ sodium carbonate; $7 \mathrm{ml}(0.09 \mathrm{~mol})$ of 1,2-dichloroethane. Previously, each initial component of the reaction mixture was dissolved in DMSO. The reaction mass was heated in a water bath $(60 \ldots 650 \mathrm{C})$ for four hours. At the end of the reaction, colorless crystals precipitated, washed with ethyl alcohol, and dried in air. The yield of hexahydro-1,2,4-triazinone-3 is 65\%. Melting point, oC: 194; IR spectrum, cm-1: 1680, 1550, 3300, 3450; Mass spectrum, m / e: 101.057, 81.092.

\section{Results and discussion}

We have developed methods for obtaining various derivatives of asymmetric triazines. This paper presents the results of testing the biological activity of a 1,2,4-triazine compound: hexahydro-1,2,4-triazinone-3 [10, 11]. 2.

Hexahydro-1,2,4-triazinone-3 was prepared according to the following scheme, scheme

The reaction of 1,2-dichloroethane with semicarbazide refers to a bimolecular nucleophilic substitution. In this case, the substrate reacts with the nucleophile by means of an electron-deficient carbon atom, therefore, the bond break in the original substrate and the formation of a bond with the nucleophile happens in one stage. The intermediate compound of this reaction is characterized by a high activation energy value and the reaction proceeds very slowly [12]. 


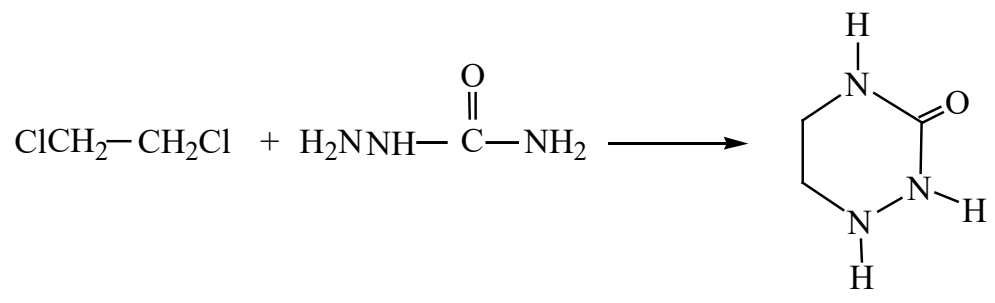

Fig. 2. Scheme for obtaining 1,2,4-triazinone-3.

The interaction of 1,2-dichloroethane with semicarbazide passes through the stage of formation of an intermediate product -1-chloroethylsemicarbazide, the isolation of which was the most difficult task, which is most likely due to its high reactivity in comparison with the initial compounds.

In order to determine the optimal conditions for the condensation reaction of 1,2dichloroethane with semicarbazide, at which the output of the target product is obtained, the effect of the reaction duration, temperature, and properties of solvents on the output of the target triazine was studied.

The study of the reaction duration was carried out in the range from one to five hours, the optimal temperature is $60 \ldots 65^{\circ} \mathrm{C}$. When the temperature decreases to $50^{\circ} \mathrm{C}$, the reaction does not proceed, an intermediate product is detected in the reaction mixture in small quantities, and when the temperature increases above $65^{\circ} \mathrm{C}$, the yield of hexahydro-1,2,4triazinone- 3 drops sharply due to the formation of a byproduct - hydrazodicarbonamide. It is optimal to carry out the reaction for 4 to 4.5 hours, at which maximum yield is achieved. Further increase in the reaction duration does not lead to a significant increase in the yield of the target triazine.

Condensation of 1,2-dichloroethane with semicarbazide refers to reactions of nucleophilic interaction of halogenalkanes with nitrogen-containing nucleophiles, the course of which depends on the nature of the solvent. Therefore, when studying this reaction, we tested both proton and aprotic solvents: ethanol, methanol, DMFA, DMSO, acetone, toluene, acetonitrile, acetic acid, and water. Proton solvents can form hydrogen bonds, dipolar aprotic solvents do not form hydrogen bonds, but their molecules are highly polar. As a result, for the reaction, we chose solvents whose dielectric constant is greater than 15 .

The highest yields of the target product were obtained using aprotic solvents, which corresponds with the theoretical rules [13,14].

The maximum yield of hexahydro-1,2,4-triazinone-3 (65\%) was achieved during synthesis in DMSO, that is in a solvent with the highest value of ionic strength and dielectric constant. The interaction of 1,2-dichloroethane and semicarbazide molecules is caused not only by intermolecular, but also by specific forces associated with the formation of donor-acceptor mechanism bonds. The reaction of nucleophilic substitution of halogenalkanes with nitrogen-containing nucleophiles is greatly influenced by the solvation of the outgoing anion, which is carried out with the participation of hydrogen bonds.

We determined the biological activity of hexahydro-1,2,4-triazinone-3. Laboratory and vegetation tests were carried out $[15,16]$. Laboratory biological tests were performed using the following method. Seeds of wheat, cucumbers, radishes, vetch laid out in Petri dishes and poured $4 \mathrm{ml}$ of the working solution. Then the Petri dishes were placed in a thermostat for two days at a temperature of $27^{\circ} \mathrm{C}$. The working concentration of the drugs are 1 and 10 $\mathrm{mg} / \mathrm{l}$. Repeatability of each option is $4-$ fold. The effectiveness of the compounds was determined two days later by the length (l) and mass (m) of the etiolated sprouts.

The results of the experiment are shown in the table 1 . 
Table 1. Biological effectiveness of the claimed growth-stimulating agent in laboratory experiments, \%.

\begin{tabular}{|c|c|c|c|c|c|c|c|c|c|}
\hline \multirow{2}{*}{$\begin{array}{c}\text { Experience } \\
\text { option }\end{array}$} & $\begin{array}{c}\text { Concentration, } \\
\mathrm{mg} / \mathrm{l}\end{array}$ & \multicolumn{2}{|c|}{ Wheat } & \multicolumn{2}{c|}{ Cucumbers } & \multicolumn{2}{c|}{ Radishes } & \multicolumn{2}{|c|}{ Vetch } \\
\cline { 3 - 10 } & $\mathrm{1}$ & $\mathrm{m}$ & $\mathrm{l}$ & $\mathrm{m}$ & $\mathrm{l}$ & $\mathrm{m}$ & 1 & $\mathrm{M}$ \\
\hline control & 0 & 100 & 100 & 100 & 100 & 100 & 100 & 100 & 100 \\
\hline prototype* & 1 & 117 & 114 & 108 & 109 & 112 & 110 & 105 & 102 \\
\hline $\begin{array}{c}\text { hexahydro- } \\
1,2,4- \\
\text { triazinone-3 }\end{array}$ & 10 & 117 & 112 & 102 & 100 & 108 & 110 & 100 & 102 \\
\hline
\end{tabular}

Vegetative biological tests were carried out according to the method. Treated seeds of barley, wheat, and rye with preparations of $10 \mathrm{mg} / \mathrm{l}$ concentration were sown in growing vessels with a diameter of $25 \mathrm{~cm}$. the Repeatability of each variant was 4-fold. Two weeks after sowing, the length (1) and mass (m) of the plants were measured. The results of vegetation tests of the biological activity of hexahydro-1,2,4-triazinone-3 are shown in rable 2.

Table 2. Growth stimulating activity of the claimed growth stimulating agent, $\%$

\begin{tabular}{|c|c|c|c|c|c|c|c|}
\hline \multirow{2}{*}{$\begin{array}{c}\text { Experience } \\
\text { option }\end{array}$} & \multirow{2}{*}{$\begin{array}{c}\text { Concentration, } \\
\mathrm{mg} / \mathrm{l}\end{array}$} & \multicolumn{2}{|c|}{ Barley } & \multicolumn{2}{|c|}{ Wheat } & \multicolumn{2}{|c|}{ Rye } \\
\cline { 3 - 8 } & 0 & 1 & $\mathrm{~m}$ & 1 & $\mathrm{~m}$ & 1 & $\mathrm{~m}$ \\
\hline control & 10 & 110 & 105 & 117 & 113 & 119 & 112 \\
\hline prototype & 10 & 117 & 119 & 119 & 123 & 125 & 122 \\
\hline $\begin{array}{c}\text { hexahydro- } \\
1,2,4- \\
\text { triazinone-3 }\end{array}$ & 0 & 100 & 100 & 100 & 100 & 100 \\
\hline
\end{tabular}

The data given in tables 1, 2 show that hexahydro-1,2,4-triazinone-3 at a concentration of 1-10 mg / 1 exhibits a stimulating effect. Therefore, hexahydro-1,2.4-triazinone-3 can be recommended for wide trials with the prospect of using in the cultivation of barley, wheat and rye.

\section{Conclusion}

A new eco-friendly plant growth and development regulator, hexahydro-1,2,4-triazinone-3, has been obtained. The results of tests of the biological and growth-stimulating activity of the target product showed that the use of this drug causes an increase in the mass of seedlings in barley by $119 \%$, in wheat by $123 \%$, in rye by $122 \%$ and an increase in the length of seedlings in wheat by $117 \%$, in wheat by $119 \%$ and rye by $125 \%$. To determine the selective activity, the dose of application and the method of application of the proposed compounds, it is necessary to conduct more extensive tests. 


\section{References}

1. D.L. Rahmankulov, G.G. Bazunova, R.S. Musavirov, A.P. Klevtsova, M.S. Kireeva and F.N.Latypova, Plant growth and development regulators 1, 196 (1999)

2. E.M. Movsumzade, R.B. Valitov, G.G. Bazunova and G.K. Aminova. Growth regulators and crops 208 (Reagent, Ufa, 2000)

3. M.A. Ikrina and A.M. Kolbin, Plant Growth and Development Regulators 1, 696, (2004)

4. V.A. Zakharenko and A.F. Chenkin, Plant protection1, 4-9 (1995)

5. D.Dzh. Nikell, Regulators of growth of plants. Application in agriculture, 189 (Kolos, Moscow, 1984)

6. N.N. Melnikov, Pesticides. Chemistry, technology and applications, 712 (Chemistry, Moscow, 1987)

7. N.N. Melnikov, Pesticides and growth regulators, 576 (Chemistry, Moscow, 1995)

8. V.I. Kefeli, Natural growth inhibitors and phytohormons, 253 (Science, Moscow, 1974)

9. N.N. Melnikov and Yu.A. Baskakov, Chemistry of herbicides and plant growth regulators, 723 (State chemical publishing house, Moscow, 1962)

10. A.K. Mazitova, V.H. Hamayev, E.S. Ulyamayeva and I.A. Sukhareva, Bashkir chemical J. 6, 4-9 (1999)

11. A.K. Mazitova, E.A. Builova and G.K. Aminova, Bashkir chemical J.,13, 5-9 (2006)

12. E.A. Builova, I.Sh. Mazitova, D.U. Rysayev and A.K. Mazitova, Bashkir chemical J. 13, 12-16 (2006)

13. K. Hauskroft and E. Constable, Modern Course in Organic Chemistry, 528 (Mir, Moscow, 2002)

14. A.D. Parker, Successes of modern chemistry 5, 528 (1968)

15. A.K. Mazitova, G.K. Aminova, E.A. Builova, M.V. Bazunova and I.S. Ingram. Russian Federation Patent No. 2, 379, 891 (2010)

16. E.A. Builova1, A.K. Mazitova1, G.U. Yarmuhametova, IOP Conf. Series: Earth and Environmental Science 459, 042017 (2020) 